\title{
Priority Rankings of Patient-Reported Outcomes for Pancreatic Ductal Adenocarcinoma: A Comparison of Patient and Physician Perspectives
}

\author{
Michelle Guan, BS¹; Gillian Gresham, PhD¹; Arvind Shinde, MD, MPH²; Isaac Lapite, BS; Jun Gong, MD; \\ Veronica R. Placencio-Hickok, PhD ${ }^{1}$; Christopher B. Forrest, MD, PhD ${ }^{3}$; and Andrew E. Hendifar, MD, MPH ${ }^{1}$
}

\section{ABSTRACT}

Background: Pancreatic ductal adenocarcinoma (PDAC) is associated with high symptom burden. However, treatment decisions currently depend heavily on physician interpretation of clinical parameters and may not consider patients' health preferences. The NIH Patient-Reported Outcomes Measurement Information System (PROMIS) initiative standardized a set of patient-reported outcomes for use in chronic diseases. This study identifies preference rankings among patients with PDAC and physicians for PROMIS domains and compares the priorities of patients and their providers. Methods: We condensed the $96 \mathrm{NIH}$ PROMIS adult domains into 31 domains and created a Maximum Difference Scaling questionnaire. Domain preference scores were generated from the responses of patients with PDAC and physicians, which were compared using Maximum Difference Scaling software across demographic and clinical variables. Results: Participants included 135 patients with PDAC $(53 \%$ male; median age, 68 years) and 54 physicians ( $76 \%$ male; median years of experience, 10). Patients selected physical functioning (PF) as their top priority, whereas physicians identified pain as most important. PF, ability to perform activities of daily living, and symptom management were within the top 5 domains for both patients and physicians, and varied only slightly across age, sex, and ethnicity. However, several domains were ranked significantly higher by patients than by physicians, including but not limited to PF; ability to do things for yourself, family, and friends; ability to interact with others to obtain help; and sleep quality. Physicians ranked pain, anxiety, and depression higher than patients did. Conclusions: Our findings suggest that patients with PDAC value PF and engaging in daily and social activities the most, whereas physicians prioritize symptoms such as pain. Patient-reported outcomes need to become more integrated into PDAC care and research to better identify unmet patient needs, inform treatment decisions, and develop therapies that address outcomes valued by patients.

J Natl Compr Canc Netw 2020;18(8):1075-1083 doi: $10.6004 /$ jnccn.2020.7548

${ }^{1}$ Cedars-Sinai Samuel Oschin Comprehensive Cancer Institute, Los Angeles, California; ${ }^{2}$ Department of Hematology and Oncology, Transplant and Hepatopancreatobiliary Institute, St. Vincent Medical Center, Los Angeles, California; and ${ }^{3}$ Applied Clinical Research Center, Children's Hospital of Philadelphia, Philadelphia, Pennsylvania.

\section{Background}

Pancreatic ductal adenocarcinoma (PDAC) is one of the most lethal cancers in the United States, with a 5-year survival rate of approximately $9 \% .{ }^{1}$ Pancreatic cancer currently represents the third leading cause of cancer mortality in the United States and is expected to become the second leading cause of cancer-related death by $2030 .{ }^{2}$ Because of the often asymptomatic nature of PDAC during early stages, $80 \%$ to $90 \%$ of patients with PDAC have unresectable tumors at presentation, with therapeutic options that are noncurative and often accompanied by serious toxicities and symptoms. ${ }^{3,4}$ The high disease burden of PDAC notably affects the health-related quality of life (HRQoL) of patients, making it essential for patient preferences and goals to be adequately considered when treatment decisions are made. ${ }^{5}$

Historically, priorities in oncology emphasized clinical outcomes and the evaluation of tumor response based on physician interpretation of parameters such as laboratory values, tumor markers, and imaging. It is increasingly recognized that these clinically oriented metrics used to assess efficacy in clinical trials do not reflect the patient's lived experience of their illness and treatments. ${ }^{6-8}$ Consequently, patient-reported outcomes (PROs) have increased in importance because of their ability to capture outcomes important to patients, such as impact of treatment adverse effects on daily functioning, emotional wellbeing, health perceptions, and satisfaction with care.,10

In the 1980s, the still widely used EORTC Quality of Life Questionnaire (QLQ-C30) and the Functional Assessment of Cancer Therapy-General (FACT-G) questionnaire were developed. ${ }^{11,12}$ These questionnaires were developed without formal patient involvement and cover markedly different aspects of HRQoL, with the EORTC QLQ-C30 emphasizing physical domains more than the

See JNCCN.org for supplemental online content. 
FACT-G questionnaire. ${ }^{11-13}$ Because multiple PRO instruments exist, the comparability of PRO data across patient care and research is suboptimal. To address these shortcomings, the NIH initiated the Patient-Reported Outcomes Measurement Information System (PROMIS) program in 2004 to standardize PRO item banks, resulting in the development of 96 PROMIS adult domains assessing aspects of patient-reported physical, mental, and social health. ${ }^{14,15}$ However, because PROMIS domains were developed for use in any disease or clinical population, the spectrum of health domains included may have varying relevance to patients with PDAC as opposed to other chronic conditions. Furthermore, studies have established that patients with cancer with shorter estimated survival times, such as those with PDAC, report greater limitations in their ability to work, poorer mental health, more fatigue, and overall greater burden than patients with other cancer types. ${ }^{16,17}$ Despite the distinct burdens of patients with PDAC, it is still poorly understood which domains of the PROMIS item banks are prioritized by these patients. After a 2016 study of patients with pancreatic cancer reported differences in the health values of patients and their healthcare providers, it became crucial to identify and address the specific inconsistencies in the health priorities of patients with PDAC and their providers. ${ }^{18}$

The purpose of this study was to establish the highestpriority PROMIS domains for patients with PDAC and compare the priorities among patients with PDAC and physician providers. By developing a focused tool for patients with PDAC using previously validated domains from the PROMIS initiative, we contrasted these patients' reports with those of other clinical populations and hoped to increase the consistency and efficiency of PRO use in both clinical care and novel therapy development for PDAC. We also hoped to identify improvement areas for achieving more patient-centered care across this disease population.

\section{Methods}

\section{Participants}

With Cedars-Sinai Medical Center Institutional Review Board approval, we identified patients with histologically confirmed PDAC receiving care between June 2017 and June 2019 and gained their consent to participate in the survey. Only English-speaking patients aged $>18$ years were included.

PDAC physician specialists at sites belonging to the Pancreatic Cancer Action Network Precision Promise Clinical Trial Consortium and additional institutions across the United States and Canada were identified and recruited through electronic communication. Medical, radiation, and surgical oncologists and gastroenterologists and palliative care specialists who treated or managed patients with PDAC as part of their clinic in the past or present were included. A complete list of the 35 contacted academic and medical centers is provided in supplemental eTable 1, available with this article at JNCCN.org.

Patients with PDAC and physicians received identical questionnaires. Surveys were self-administered at a single time point. For each patient, demographic and clinical data, including age, sex, race/ethnicity, and disease status (unresectable or resectable), were recorded from the electronic health records. For physicians, a selfreported section asking for the physician's sex and number of years of physician experience with PDAC was included. Additional information regarding the physician's institution was separately recorded by study staff. Patients completed the survey on a tablet, whereas physicians completed it through an email link.

\section{Survey Development}

Each of the 96 adult PRO domains from the PROMIS initiative were considered in the study's "PancPROMIS" survey, informed by the literature and previously established core outcome sets for pancreatic cancer and a consensus-based approach. ${ }^{19,20}$ Using a consensus-based approach, 2 medical oncologists (A.S. and A.E.H.) specializing in the care of patients with PDAC independently screened the 96 PROMIS domains for adults to evaluate relevancy to PDAC (Figure 1). ${ }^{21}$ Overlapping domains were grouped and summarized as displayed in supplemental eTable 2. PRO domains identified as infrequent or overly specific, including substance abuse (alcohol, smoking) and itching, were excluded. Any discrepancies in selection of PROMIS domains were resolved through discussion at weekly meetings, and additional discrepancies were resolved by a third investigator (V.R.P.H.). The final PancPROMIS survey included 31 domains across 4 categories: global health (1 domain), mental health (11 domains), physical health (12 domains), and social health (7 domains) (supplemental eFigure 1). Maximum Difference Scaling (MaxDiff) software (Lighthouse Studio, Sawtooth Software) was used to create the final survey. The 31 PRO domains were displayed in a series of 20 questions generated by the MaxDiff software, with each domain appearing 3 or 4 times as determined by the software algorithm. For each question, participants were given a list of 5 PROMIS domains and asked, "Please choose the most important aspect/domain and the least important aspect/domain of HRQoL when assessing someone with pancreatic cancer" (supplemental eFigure 2).

\section{Statistical Analysis}

Descriptive analyses were reported to characterize the patient and physician populations. Demographic and clinical factors were expressed appropriately as continuous (means and standard errors [SEs]) or categorical variables (frequencies and percentages). Preference scores for each 


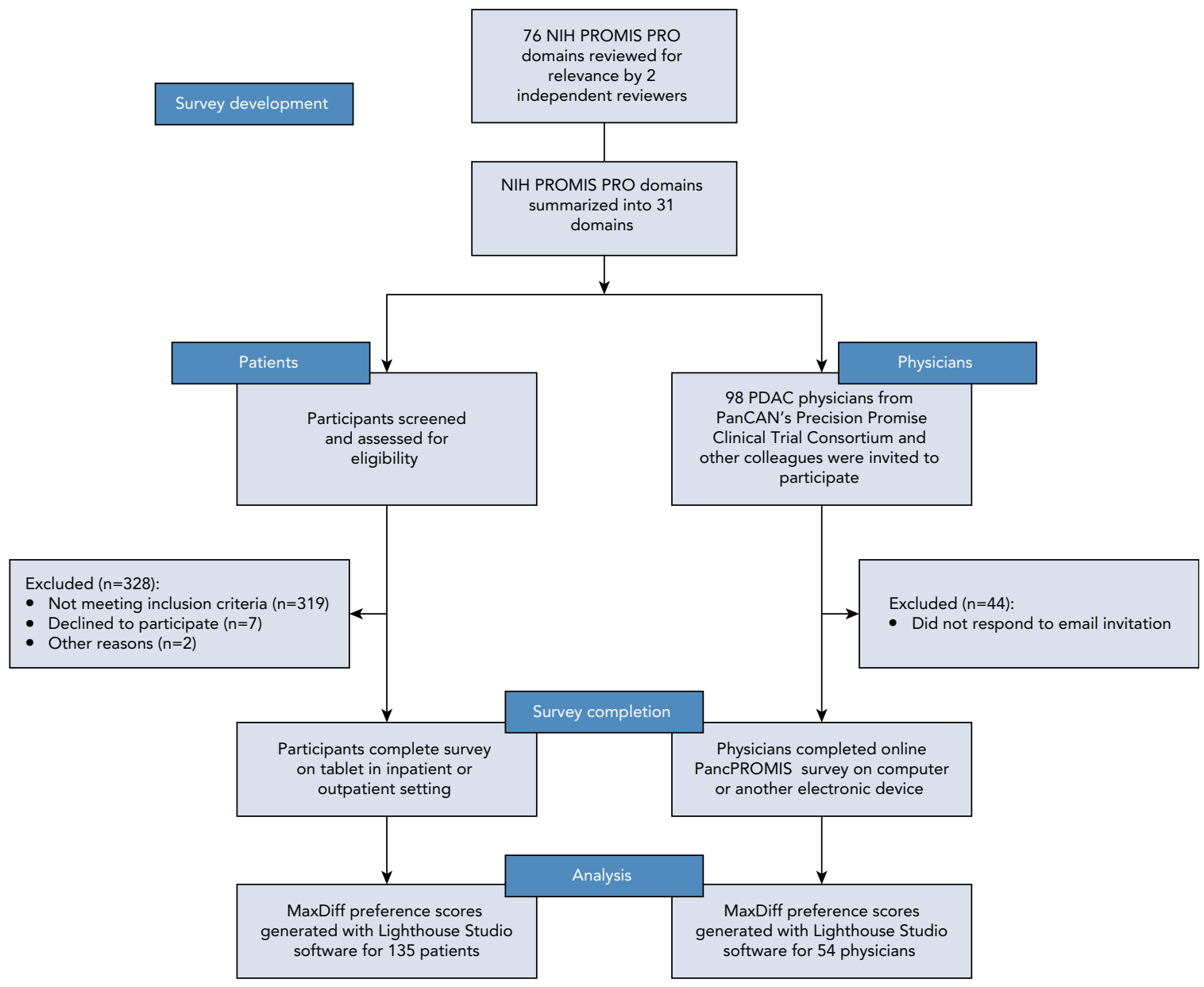

Figure 1. Flowchart of study procedures.

Abbreviations: MaxDiff, Maximum Difference Scaling; PanCAN, Pancreatic Cancer Action Network; PDAC, pancreatic ductal adenocarcinoma; PRO, patient-reported outcome; PROMIS, Patient-Reported Outcomes Measurement Information System.

of the 31 PRO items were generated and ranked separately for physicians and patients using the MaxDiff software.

Preference scores were analyzed using MaxDiff, a type of conjoint analysis, via Lighthouse Studio software.$^{18}$ MaxDiff analysis is a standard method used to rank patient preferences based on an individual's responses to a series of questions that involve selecting a single preference from among a list of options. The survey consisted of 31 items and 5 items per set, with a total of 20 sets.

Logit modeling was used to generate individual-level preference scores for each of the 31 PRO domains for patients and physicians, based on their cumulative responses. MaxDiff analysis was run for patients grouped based on age, sex, disease status, and race/ethnicity. Physicians were grouped together based on sex, specialty, years of experience treating patients with PDAC, institution type, and institution region. Preferences were reported separately for patients and physicians and by each of the previously listed variables. Rescaled scores using 0 to 100 scoring were computed to allow comparison of preferences. For example, an item with a score of 10 is twice as important/preferred as an item with a score of 5 . Raw scores and SEs were also exported from the Lighthouse Studio software, and differences in means were calculated using $t$ tests for 2 independent samples and simple linear regression.

\section{Results}

Of 328 patients screened, a total of 135 eligible patients with PDAC who were treated at Cedars-Sinai Medical Center completed this research survey between June 2017 and April 2019 (Figure 1). Participant characteristics of patients and physicians are shown in Table 1. Participants included 71 male $(52.6 \%)$ and 64 female $(47.4 \%)$ patients (mean and median, 68 years; range, 37-95 years). Of the 98 physicians contacted, 54 (55.1\%) completed the online survey, including 41 male and 13 female physicians from 25 institutions (Table 1 and supplemental eTable 1).

Preference scores for patients and physicians for each domain are presented in Table 2 and Figure 2. The top-ranked domain for patients was "ability to be 


\begin{tabular}{|c|c|}
\hline Characteristic & $n(\%)$ \\
\hline \multicolumn{2}{|l|}{ Patients with PDAC $(n=135)$} \\
\hline \multicolumn{2}{|l|}{ Sex } \\
\hline Female & $64(47.4)$ \\
\hline Male & $71(52.6)$ \\
\hline \multicolumn{2}{|l|}{ Age, $y$} \\
\hline$<60$ & $29(21.5)$ \\
\hline $60-69$ & $46(34.1)$ \\
\hline $70-79$ & $44(32.6)$ \\
\hline$\geq 80$ & $16(11.8)$ \\
\hline \multicolumn{2}{|l|}{ Race/Ethnicity } \\
\hline Non-Hispanic white & $95(70.4)$ \\
\hline Asian & $17(12.6)$ \\
\hline Hispanic & $12(8.9)$ \\
\hline Black & $8(5.9)$ \\
\hline Other & $3(2.2)$ \\
\hline \multicolumn{2}{|l|}{ Disease status } \\
\hline Resectable & $44(32.6)$ \\
\hline Unresectable & $91(67.4)$ \\
\hline \multicolumn{2}{|l|}{ PDAC physicians $(n=54)$} \\
\hline \multicolumn{2}{|l|}{ Sex } \\
\hline Male & $41(75.9)$ \\
\hline Female & $13(24.1)$ \\
\hline \multicolumn{2}{|l|}{ Physician specialty } \\
\hline Medical oncology & $34(63)$ \\
\hline Radiation oncology & $2(3.7)$ \\
\hline Surgical oncology & $9(16.7)$ \\
\hline Gastroenterology & $7(12.9)$ \\
\hline Palliative care & $2(3.7)$ \\
\hline \multicolumn{2}{|c|}{ Years treating patients with PDAC } \\
\hline $1-5$ & $11(2.4)$ \\
\hline $6-10$ & $18(33.3)$ \\
\hline $11-15$ & $9(16.7)$ \\
\hline$\geq 16$ & $14(2.6)$ \\
\hline NR & $1(1.9)$ \\
\hline \multicolumn{2}{|l|}{ Institution type } \\
\hline Academic & $52(96)$ \\
\hline Nonacademic & $2(4)$ \\
\hline \multicolumn{2}{|l|}{ Institution region } \\
\hline West Coast, United States & $30(55.6)$ \\
\hline East Coast, United States & $10(18.5)$ \\
\hline Midwest, United States & $2(3.7)$ \\
\hline South, United States & $6(11.1)$ \\
\hline Canada & $6(11.1)$ \\
\hline
\end{tabular}

Abbreviations: NR, not reported (missing response from one participant); PDAC, pancreatic ductal adenocarcinoma. physically functional" (physical functioning $[\mathrm{PF}]$ domain), with a mean preference score of 0.48 (SE, 0.12) and rescaled value of 7.49, whereas the lowest-ranked domain was "anger," with a mean preference score -2.81 (SE, 0.13) and rescaled value of 0.57 . PF was thus ranked 15 times as important as anger among patients. Among physicians, "pain and its effect on life" was ranked highest (mean, 0.70; SE, 0.20) with a rescaled value of 8.32, and "sexual satisfaction and functioning" was ranked lowest (mean, -3.58 ; SE, 0.22 ) with a rescale score of 0.32 (Table 2).

Pain $(P<.001)$, anxiety/fear $(P=.001)$, and depression/ sadness $(P<.001)$ were ranked significantly higher in importance by physicians than by patients. $\mathrm{PF}(P<.05)$; ability to do things for yourself, family, and friends $(P<.049)$; ability to interact with others to obtain help $(P=.006)$; and sleep quality $(P<.001)$ were among some of the domains ranked significantly higher by patients than by physicians. Among the domains ranked similarly by physicians and patients are fatigue and its impact on functioning $(P=.442)$, ability to manage recommended medications and treatments $(P=.412)$, and diarrhea $(P=.279)$, which are domains important for patients in their HRQoL through day-to-day activities and for providers as a means of assessing clinical improvement or response to various interventions. Additional comparisons in mean priority scores between patients and physicians are displayed in Figure 3.

Overall, PF was ranked highest by patients across most subgroups, including sex and age and among nonHispanic white patients (supplemental eTable 3). The social and mental aspects of health, including the ability to perform daily activities, participate in work and social activities, do things for oneself, and ability to manage symptoms, were among the top 5 ranked preferences of all patients $(n=135)$ and in adults aged $<65$ years, women, men, and white patients. General well-being was among the top 5 ranked items by men, Hispanic patients, and Asian patients, whereas sleep quality appeared in the top 5 ranked items only for Asian patients. Physicians rated pain and its effect on life to be most important, followed by the ability to perform daily activities (mental), ability to manage symptoms (mental), ability to be physically functional (physical), and general well-being (general) (supplemental eTable 3).

\section{Discussion}

To our knowledge, this is the first study reporting PDACspecific patient and physician rankings of the priorities of the NIH's PRO domains as determined for 135 patients with PDAC and 54 PDAC physician specialists. This study compares the variations in the health priorities of patients with PDAC and their providers, specifically the importance patients placed on PF and autonomy to perform daily and social activities, as opposed to PDAC physicians' current emphasis on pain. These findings can inform 
Table 2. Preference Scores and Rankings by Patients With PDAC and Physicians

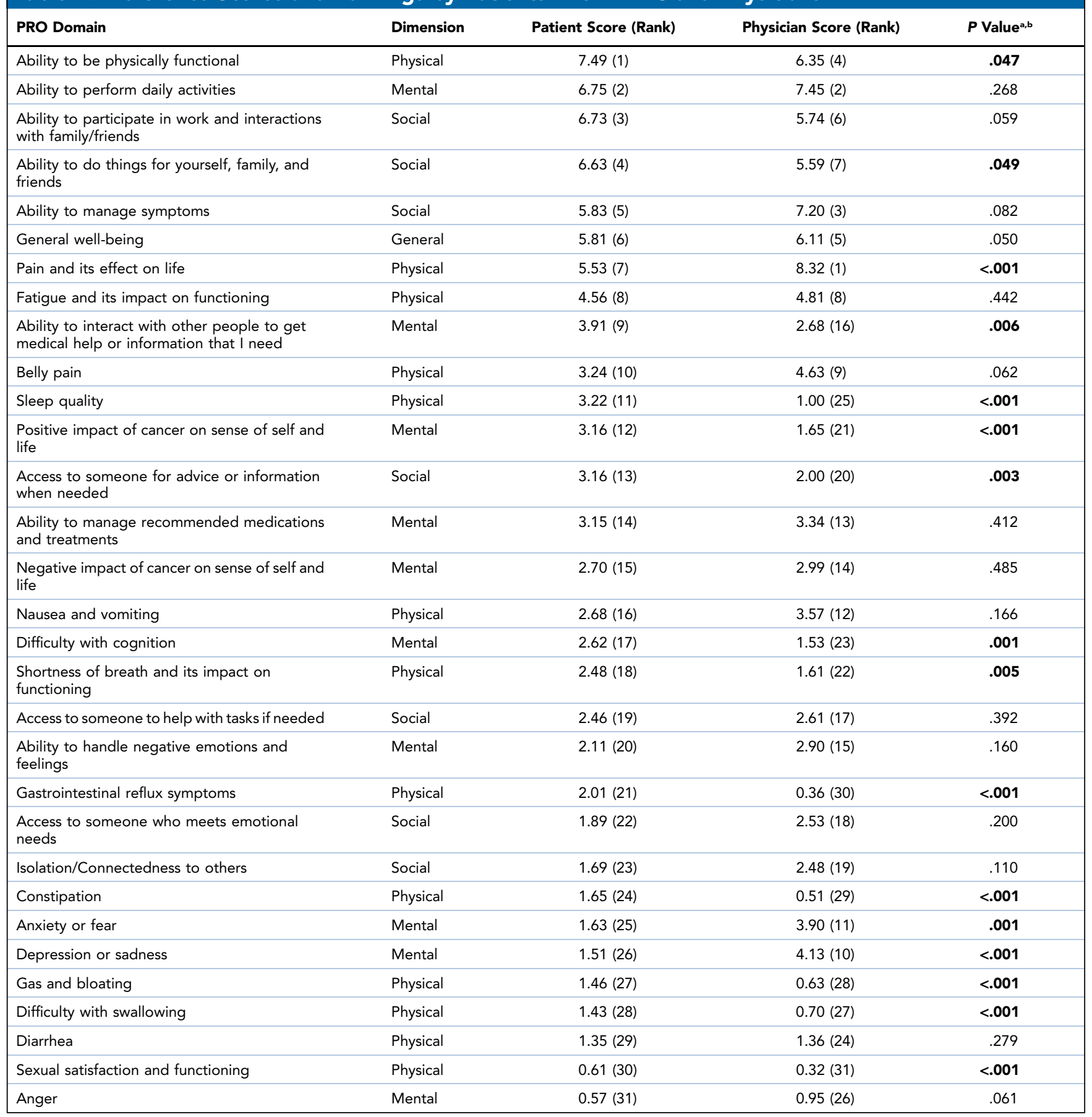

Abbreviations: PDAC, pancreatic ductal adenocarcinoma; PRO, patient-reported outcome.

${ }^{a} t$ test was used to calculate differences in rescaled raw scores.

${ }^{b}$ Bold indicates statistically significant $P$ values.

PDAC providers regarding ways to achieve more patientcentered care, and facilitate the design of PDAC trials that address outcomes identified as important by patients.

In the past few decades, there has been increased emphasis on the use of PROs to improve shared decision-making between patients and physicians. However, there is limited research on the relevancies of the numerous available PROs to patients with PDAC and whether these align with what their physicians believe are patient priorities. In a 2016 study that observed 
A

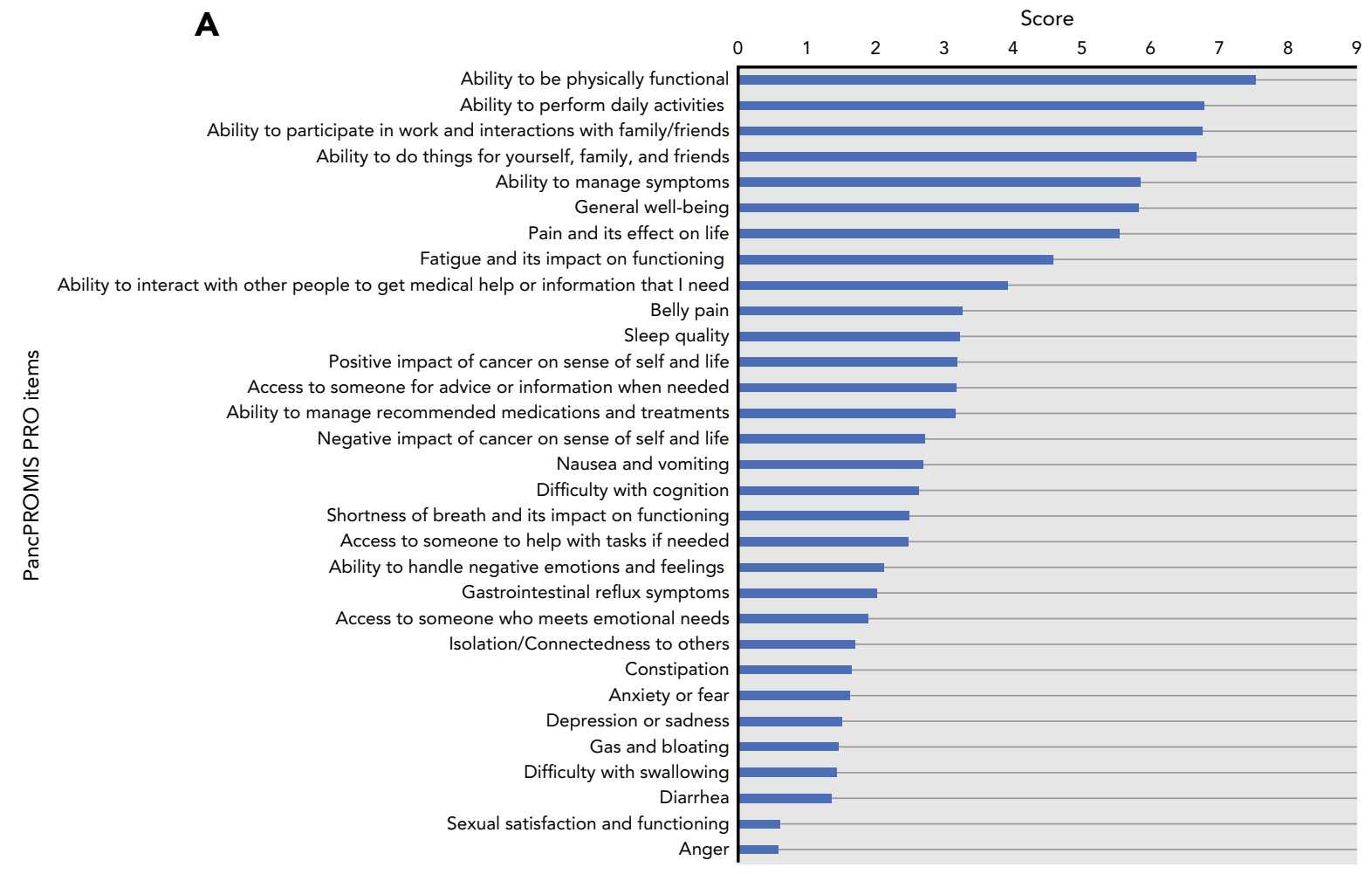

B

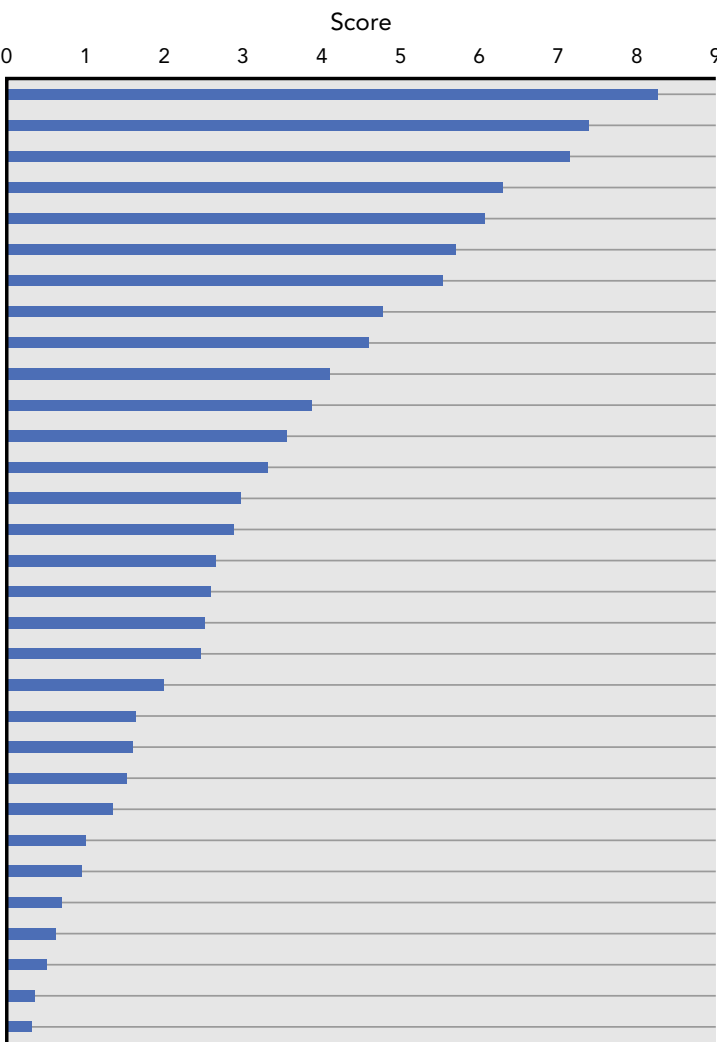

Figure 2. Preference rankings of $P R O$ items among (A) patients with PDAC $(n=135)$, and (B) PDAC physicians $(n=54)$.

Abbreviations: PDAC, pancreatic ductal adenocarcinoma; PRO, patient-reported outcome. 


\begin{tabular}{|c|c|c|c|c|}
\hline \multirow{2}{*}{$\begin{array}{l}\text { PROMIS Item } \\
\text { Physical }\end{array}$} & \multicolumn{2}{|c|}{$\begin{array}{l}\text { SMDs } \\
\text { Physician and Patient PROMIS Scores }\end{array}$} & \multirow[t]{2}{*}{ SMD $(95 \% \mathrm{Cl})$} & \multirow{2}{*}{ Weight } \\
\hline & & & & \\
\hline Ability to be physically functional & $\longrightarrow$ & & $-0.28(-0.60,0.04)$ & 3.39 \\
\hline Belly pain & & $t \rightarrow$ & $0.26(-0.06,0.57)$ & 3.40 \\
\hline Constipation & $\longrightarrow$ & & $-0.94(-1.27,-0.61)$ & 3.13 \\
\hline Diarrhea & & & $-0.10(-0.41,0.22)$ & 3.42 \\
\hline Difficulty with swallowing & $\longrightarrow$ & & $-0.62(-0.94,-0.30)$ & 3.29 \\
\hline Fatigue and its impact on functioning & & & $-0.02(-0.34,0.29)$ & 3.42 \\
\hline Gas and bloating & $\longrightarrow$ & & $-0.71(-1.04,-0.39)$ & 3.25 \\
\hline Gastrointestinal reflux symptoms & $\multimap$ & & $-1.35(-1.70,-1.01)$ & 2.88 \\
\hline Nausea and vomiting & & 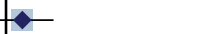 & $0.16(-0.15,0.48)$ & 3.41 \\
\hline Pain and its effect on life & & $\longrightarrow$ & $0.54(0.22,0.86)$ & 3.32 \\
\hline Sexual satisfaction and functioning & $\rightarrow-$ & & $-0.55(-0.87,-0.23)$ & 3.32 \\
\hline Shortness of breath and its impact on functioning & $\rightarrow$ & & $-0.44(-0.76,-0.12)$ & 3.35 \\
\hline Sleep quality & $\longrightarrow$ & & $-1.01(-1.34,-0.68)$ & 3.09 \\
\hline \multicolumn{5}{|l|}{ Mental } \\
\hline Ability to do things for yourself, family, and friends & $\longrightarrow$ & & $-0.28(-0.59,0.04)$ & 3.39 \\
\hline Ability to handle negative emotions and feelings & & $\leftarrow$ & $0.17(-0.15,0.48)$ & 3.41 \\
\hline Ability to interact with other people to get medical help or inforr & lation that I need & & $-0.43(-0.74,-0.11)$ & 3.36 \\
\hline Ability to manage recommended medications and treatments & & - & $-0.04(-0.35,0.28)$ & 3.42 \\
\hline Ability to perform daily activities & & - & $0.10(-0.21,0.42)$ & 3.42 \\
\hline Anger & & $\rightarrow-$ & $0.25(-0.06,0.57)$ & 3.40 \\
\hline Anxiety or fear & & $\multimap-$ & $0.64(0.32,0.96)$ & 3.28 \\
\hline Depression or sadness & & 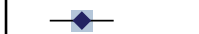 & $0.75(0.43,1.08)$ & 3.23 \\
\hline Difficulty with cognition & $\rightarrow-$ & & $-0.52(-0.84,-0.20)$ & 3.33 \\
\hline Negative impact of cancer on sense of self and life & & & $-0.01(-0.32,0.31)$ & 3.42 \\
\hline Positive impact of cancer on sense of self and life & $\longrightarrow$ & & $-0.62(-0.95,-0.30)$ & 3.29 \\
\hline \multicolumn{5}{|l|}{ Social } \\
\hline Ability to manage symptoms & & - & $0.23(-0.09,0.55)$ & 3.40 \\
\hline Ability to participate in work and interactions with family/friends & $\rightarrow-1$ & & $-0.26(-0.58,0.06)$ & 3.40 \\
\hline Access to someone for advice or information when needed & $\rightarrow-$ & & $-0.47(-0.79,-0.15)$ & 3.34 \\
\hline Access to someone to help with tasks if needed & & - & $-0.05(-0.36,0.27)$ & 3.42 \\
\hline Access to someone who meets emotional needs & & to & $0.14(-0.18,0.46)$ & 3.41 \\
\hline Isolation/Connectedness to others & & 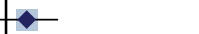 & $0.21(-0.11,0.52)$ & 3.41 \\
\hline-4 & -1 & 1 & 3 & \\
\hline
\end{tabular}

Figure 3. Differences in mean preference scores between patients with pancreatic ductal adenocarcinoma and physicians, grouped by domain $\mathrm{SMD}=0$, no difference in preferences between physicians and patients; $\mathrm{SMD}>0$, physicians scored higher than patients; $\mathrm{SMD}<0$, patients scored higher than physicians. The dotted red line indicates overall SMDs in priority scores between patients and physicians.

Abbreviations: PROMIS, Patient-Reported Outcomes Measurement Information System; SMD, standardized mean difference.

patients with pancreatic cancer during their care, contradictions were revealed between medical staff preconceptions of patient experiences and what patients reported, including assumptions that long-term survival outcomes are most important for these patients. ${ }^{18}$ This study illustrated that discrepancies in health values between patients with PDAC and their providers exist, which we further examined through individual-level guidance from patients and physicians.

In our study, we found that patients placed significantly higher value than physicians on their ability to engage in social interactions and independently do things for themselves and for others. The top 5 patient health priorities included statements beginning with "ability to," emphasizing patient desires for preserving autonomy and minimizing disease-related disruptions in their lives. Unfortunately, these social health and role function domains are currently understudied and underused in PDAC..$^{22}$ In 2013, one of the first pancreatic cancer PRO tools was developed: the Pancreatic Cancer Disease Impact score, which is calculated from 8 health domains of pain, fatigue, anxiety, bowel problems, loss of appetite, dry mouth, itchiness, and nausea. ${ }^{23}$ Notably, these items are predominantly disease-related physical symptoms, which have been shown to be lower-priority concerns for patients with PDAC in our study and more recent PRO studies. ${ }^{24}$ Similarly, the PROMIS questionnaire contains a larger percentage of questions relating to physical health than those concerning mental or social health (supplemental eFigure 1). Furthermore, the 26question EORTC QLQ-PAN26 assessment tool that was designed to be used in conjunction with the 30-question EORTC QLQ-C30 contains an overwhelming number of questions with emphasis on highly specific physical symptoms that are not of top-priority interest to patients with PDAC. ${ }^{24}$ 
Our study also noted that physicians ranked pain, anxiety, and depression of greater importance than patients did, which is consistent with the results of the 2017 Core Set of Patient-Reported Outcomes in Pancreatic Cancer study, which used a Likert scale design to survey patients with pancreatic cancer and providers. ${ }^{20}$ In our study, pain and its impact on life was ranked highest by physicians, whereas patients ranked it as the sixth most important. Interestingly, pain, anxiety, and depression represent some of the most commonly cited symptoms reported in advanced cancers. ${ }^{25}$ The benefits of palliative care integration into oncology care, as recommended in the 2016 ASCO clinical practice guideline update, are also becoming more recognized and may also contribute to this increased focus on symptoms such as pain. ${ }^{26}$ To demonstrate this point, palliative care programs in American hospitals have tripled since 2000. ${ }^{27}$

Although palliative care often focuses on addressing immediate physical, psychologic, and social distress concerns related to HRQoL, the solutions offered are frequently short term and centered on the management of complex or refractory symptoms. ${ }^{28}$ Conversely, rehabilitation services focus more on long-term solutions for restoration and optimal function at home, at work, and in the community through interventions addressing the physical, psychologic, and vocation-related impairments that patients with cancer may encounter. ${ }^{29,30}$ Our study showed that PF was ranked as the top priority for patients and a top 5 priority for physicians, revealing a consensus understanding of patients' desires to resume daily activities and self-sufficient lifestyles. Unfortunately, cancer rehabilitation services are still underused, despite numerous studies documenting improvements in general well-being, symptom severity, physical performance status, and HRQoL in patients with advanced cancer with the incorporation of a rehabilitation program..$^{18,30-33}$

Routine multidisciplinary consultation with services such as supportive care, nutrition, genetic counseling, and social services should also be used to understand each patient's unique perspectives, questions, and concerns. Support and patient advocacy groups can also aid patient understanding of potential treatmentrelated ramifications and how they may impact domains of importance to patients. A multidisciplinary focus, in addition to services tailored to improving $\mathrm{PF}$ and other disease-related processes affecting $\mathrm{PF}$, is necessary to minimize discord between patients and providers and move toward a more patient-centered, shared-decision-making approach to care.

It should be noted that this study is limited by its single-institution design, cross-sectional nature, imbalances in provider characteristics, and heterogeneity in patients' treatment and disease courses. Expanding this study into a multicenter longitudinal study over multiple time points to capture potential changes in priorities across patients' disease courses and compare across predefined patient characteristics would enhance the generalizability of our findings and further validate these domains. Currently, however, this study has identified opportunities for patient care HRQoL intervention, especially among patients with unresectable PDAC.

\section{Conclusions}

Identifying patients priorities is the first step toward encouraging the medical community to recommend these desired multidisciplinary services to colleagues, patients, and families earlier in the continuum of care. Through integration of additional interdisciplinary services in earlier phases of PDAC care, the severity of treatmentrelated impairments that later develop may be reduced, which is especially relevant to a high-symptom burden disease such as PDAC. Further research on the feasibility of incorporating PROs in pancreatic cancer care is needed so that awareness of unmet patient needs can increase and advances in patient health, function, HRQoL, and satisfaction in care can occur.

\section{Acknowledgments}

We wish to thank all the patients in our clinic who took the time to complete our survey and the physicians across the country who responded to our survey invitations. We also acknowledge the Pancreatic Cancer Action Network's Precision Promise Clinical Trial Consortium.

Submitted October 29, 2019; accepted for publication February 18, 2020.

Author contributions: Study concept and design: Guan, Gresham, Shinde, Hendifar. Data collection: Guan, Lapite. Statistical analysis: Gresham. Manuscript preparation: Guan, Gresham. Critical revisions: Guan, Gresham, Shinde, Gong, Placencio-Hickok, Forrest, Hendifar.

Disclosures: The authors have disclosed that they have not received any financial consideration from any person or organization to support the preparation, analysis, results, or discussion of this article.

Correspondence: Andrew E. Hendifar, MD, MPH, Gastrointestinal and Neuroendocrine Malignancies, Cedars-Sinai Samuel Oschin Comprehensive Cancer Institute, 8700 Beverly Boulevard, AC 1042C, Los Angeles, CA 90048. Email: andrew.hendifar@cshs.org

\section{References}

1. Pancreatic Cancer Action Network. Pancreatic cancer survival rates Accessed February 6, 2020. Available at: https://www.pancan.org/facingpancreatic-cancer/about-pancreatic-cancer/survival-rate/

2. Noone AM, Howlander N, Krapcho M, et al, eds. SEER cancer statistics review, 1975-2015, National Cancer Institute. Bethesda, MD. Available at:

https://seer.cancer.gov/csr/1975_2015/, based on November 2017 SEER data submission, posted to the SEER web site, April 2018.

3. Carrato A, Falcone A, Ducreux M, et al. A systematic review of the burden of pancreatic cancer in Europe: real-world impact on survival, quality of life and costs. J Gastrointest Cancer 2015;46:201-211. 
4. Sherman DW, McMillan SC. The physical health of patients with advanced pancreatic cancer and the psychological health of their family caregivers when newly enrolled in hospice. J Hosp Palliat Nurs 2015;17: 235-241.

5. Gordon-Dseagu VL, Devesa SS, Goggins M, et al. Pancreatic cancer incidence trends: evidence from the Surveillance, Epidemiology and End Results (SEER) population-based data. Int J Epidemiol 2018;47:427-439.

6. Kluetz PG, Chingos DT, Basch EM, et al. Patient-reported outcomes in cancer clinical trials: measuring symptomatic adverse events with the National Cancer Institute's Patient-Reported Outcomes version of the Common Terminology Criteria for Adverse Events (PRO-CTCAE). Am Soc Clin Oncol Educ Book 2016;35:67-73.

7. Mooney K, Berry DL, Whisenant M, et al. Improving cancer care through the patient experience: how to use patient-reported outcomes in clinical practice. Am Soc Clin Oncol Educ Book 2017;37:695-704.

8. Gliklich RE, Dreyer NA, Leavy MB, eds. Registries for Evaluating Patient Outcomes: A User's Guide, 3rd ed. Rockville, MD: Agency for Healthcare Research and Quality (US); 2014.

9. Bottomley A, Pe M, Sloan J, et al. Analysing data from patient-reported outcome and quality of life endpoints for cancer clinical trials: a start in setting international standards. Lancet Oncol 2016;17:e510-514.

10. Broderick JE, DeWitt EM, Rothrock N, et al. Advances in patient-reported outcomes: the NIH PROMIS measures. EGEMS (Wash DC) 2013;1:1015.

11. Atkinson TM, Stover AM, Storfer DF, et al. Patient-reported physical function measures in cancer clinical trials. Epidemiol Rev 2017;39:59-70.

12. McKenna SP. The limitations of patient-reported outcome measurement in oncology. J Clin Pathw 2016;2:37-46.

13. Kemmler G, Holzner B, Kopp M, et al. Comparison of two quality-of-life instruments for cancer patients: the Functional Assessment of Cancer Therapy-General and the European Organization for Research and Treatment of Cancer Quality of Life Questionnaire-C30. J Clin Onco 1999;17:2932-2940.

14. Cella D, Yount $S$, Rothrock N, et al. The Patient-Reported Outcomes Measurement Information System (PROMIS): progress of an NIH Roadmap cooperative group during its first two years. Med Care 2007; 45(5 Suppl 1):S3-11.

15. Chasen MR, Feldstain A, Gravelle D, et al. An interprofessional palliative care oncology rehabilitation program: effects on function and predictors of program completion. Curr Oncol 2013;20:301-309.

16. Yabroff KR, Lawrence WF, Clauser $\mathrm{S}$, et al. Burden of illness in cancer survivors: findings from a population-based national sample. J Nat Cancer Inst 2004;96:1322-1330.

17. Weaver KE, Forsythe LP, Reeve BB, et al. Mental and physical healthrelated quality of life among U.S. cancer survivors: population estimates from the 2010 National Health Interview Survey. Cancer Epidemiol Biomarkers Prev 2012;21:2108-2117.

18. Hagensen A, London AE, Phillips JJ, et al. Using experience-based design to improve the care experience for patients with pancreatic cancer. J Oncol Pract 2016;12:e1035-1041.
19. Spiegel BM, Hays RD, Bolus R, et al. Development of the NIH Patient-Reported Outcomes Measurement Information System (PROMIS) gastrointestinal symptom scales. Am J Gastroenterol 2014;109:1804-1814; erratum in: Am J Gastroenterol 2015;110:608

20. van Rijssen LB, Gerritsen A, Henselmans I, et al. Core Set of PatientReported Outcomes in Pancreatic Cancer (COPRAC): an international Delphi study among patients and health care providers. Ann Surg 2019 270:158-164.

21. Chiarotto A, Ostelo RW, Turk DC, et al. Core outcome sets for research and clinical practice. Braz J Phys Ther 2017;21:77-84

22. Petzel MQ, Parker NH, Valentine AD, et al. Fear of cancer recurrence after curative pancreatectomy: a cross-sectional study in survivors of pancreatic and periampullary tumors. Ann Surg Oncol 2012;19: 4078-4084.

23. Heiberg T, Nordby T, Kvien TK, et al. Development and preliminary validation of the pancreatic cancer disease impact score. Support Care Cancer 2013;21:1677-1684.

24. Fitzsimmons D, Johnson CD, George S, et al. Development of a disease specific quality of life ( $\mathrm{OoL})$ questionnaire module to supplement the EORTC core cancer QoL questionnaire, the QLQ-C30 in patients with pancreatic cancer. Eur J Cancer 1999;35: 939-941.

25. Donnelly S, Walsh D. The symptoms of advanced cancer. Semin Oncol 1995;22(Suppl 3):67-72

26. Ferrell BR, Temel JS, Temin S, et al. Integration of palliative care into standard oncology care: ASCO clinical practice guideline update summary. J Oncol Pract 2017;13:119-121.

27. Morrison RS, Augustin R, Souvanna $\mathrm{P}$, et al. America's care of serious illness: a state-by-state report card on access to palliative care in our nation's hospitals. J Palliat Med 2011;14:1094-1096.

28. Silver JK, Raj VS, Fu JB, et al. Cancer rehabilitation and palliative care: critical components in the delivery of high-quality oncology services. Support Care Cancer 2015;23:3633-3643.

29. Mukai A. The future of physiatry: with challenges come opportunities. PM R 2011;3:189-192.

30. Silver JK, Baima J, Mayer RS. Impairment-driven cancer rehabilitation: an essential component of quality care and survivorship. CA Cancer J Clin 2013;63:295-317.

31. Cheville AL, Troxel AB, Basford JR, et al. Prevalence and treatment patterns of physical impairments in patients with metastatic breast cancer. $\mathrm{J}$ Clin Oncol 2008;26:2621-2629.

32. Pergolotti M, Deal AM, Lavery J, et al. The prevalence of potentially modifiable functional deficits and the subsequent use of occupational and physical therapy by older adults with cancer. J Geriatr Oncol 2015;6: 194-201.

33. Salakari MR, Surakka $T$, Nurminen $R$, et al. Effects of rehabilitation among patients with advances cancer: a systematic review. Acta Oncol 2015;54:618-628. 
Supplemental online content for:

\section{Priority Rankings of Patient-Reported Outcomes for Pancreatic Ductal Adenocarcinoma: A Comparison of Patient and Physician Perspectives}

Michelle Guan, BS; Gillian Gresham, PhD; Arvind Shinde, MD, MPH; Isaac Lapite, BS; Jun Gong, MD;

Veronica R. Placencio-Hickok, PhD; Christopher B. Forrest, MD, PhD; and Andrew E. Hendifar, MD, MPH

J Natl Compr Canc Netw 2020;18(8):1075-1083

eFigure 1: Percentage of PRO Items by NIH PROMIS Category in PancPROMIS Survey

eFigure 2: Sample PancPROMIS Best/Worst Scaling Survey Questions

eTable 1: List of Participating Academic Centers

eTable 2: Evaluated PROMIS Domains

eTable 3: Top 5 Preferences Among Patients With PDAC and Physicians 


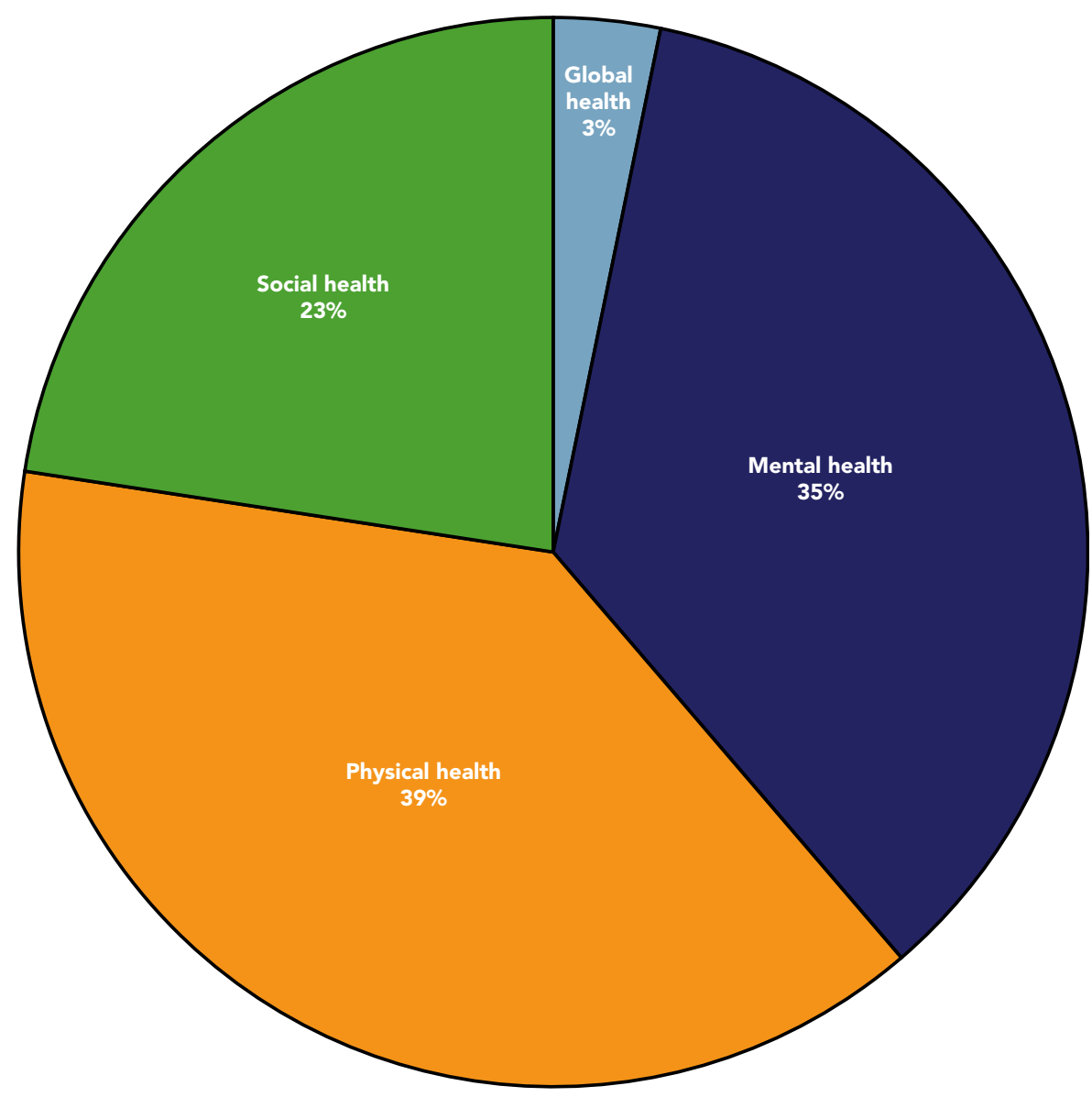

eFigure 1. Percentage of PRO items by NIH PROMIS category in PancPROMIS survey.

Abbreviations: PRO, patient-reported outcome; PROMIS, Patient-Reported Outcomes Measurement Information System.

Please choose the most important aspect/domain and the least important aspect/domain of quality of life when assessing someone with pancreatic cancer

$(5$ of 20$)$

\begin{tabular}{|c|c|c|}
\hline $\begin{array}{c}\text { Most } \\
\text { Important }\end{array}$ & Least \\
Important
\end{tabular}

Click the forward arrow to continue.

eFigure 2. Sample PancPROMIS best/worst scaling survey questions. 


\section{eTable 1. List of Participating Academic Centers}

Number of Physicians

Respondents/Number

List of Contacted Centers

Contacted

Cedars-Sinai Medical Center

$15 / 19$

City of Hope National Medical Center 2/7

Dana-Farber Cancer Institute

$0 / 1$

Duke University Medical Center

$0 / 1$

Fox Chase Cancer Center

$1 / 1$

George Washington University

$0 / 1$

Johns Hopkins University

$0 / 1$

Kaiser Permanente (Southern California)

$2 / 3$

Karmanos Cancer Center (Wayne State

University)

Massachusetts General Hospital Cancer Center

$1 / 1$

$1 / 1$

MD Anderson Cancer Center

$0 / 2$

Memorial Sloan Kettering Cancer Center

$1 / 3$

Moffitt Cancer Center

$3 / 3$

Northwestern University

$0 / 1$

New York University

$1 / 1$

Ohio State University

$2 / 2$

Ottawa Hospital

$0 / 1$

Stanford University

$4 / 5$

University of Washington

$0 / 1$

University of California

$2 / 3$

University of California, Davis $1 / 2$

University of California, Irvine $\quad 0 / 1$

University of California, Los Angeles $\quad 2 / 5$

University of California, San Diego 2/8

University of California, San Francisco $3 / 3$

$\begin{array}{ll}\text { University of Chicago } & 0 / 2\end{array}$

$\begin{array}{ll}\text { University of Florida } & 2 / 2\end{array}$

University of British Columbia 2/3

University of Calgary $\quad 0 / 1$

University of Pennsylvania $\quad 2 / 2$

University of Utah $\quad 0 / 1$

Vanderbilt University $1 / 1$

Verity Health $2 / 4$

Virginia Mason Medical Center $\quad 1 / 1$

Washington University in St. Louis $\quad 0 / 2$

West Virginia University $1 / 1$ 


\section{eTable 2. Evaluated PROMIS Domains}

\begin{tabular}{|c|c|c|c|}
\hline Adult Domain Group & Adult Domain & Included & Wording on Survey \\
\hline \multirow[t]{3}{*}{ Global } & Global health & Y & \multirow[t]{3}{*}{ General well-being } \\
\hline & Global mental & Y & \\
\hline & Global physical & Y & \\
\hline \multirow[t]{30}{*}{ Mental health } & Alcohol - alcohol use & $\mathrm{N}$ & \multirow[t]{5}{*}{ NA } \\
\hline & Alcohol - negative consequences & $\mathrm{N}$ & \\
\hline & Alcohol - negative expectancies & $\mathrm{N}$ & \\
\hline & Alcohol - positive consequences & $\mathrm{N}$ & \\
\hline & Alcohol - positive expectancies & $\mathrm{N}$ & \\
\hline & Cognitive function & Y & \multirow[t]{2}{*}{ Difficulty with cognition } \\
\hline & Cognitive function - abilities & Y & \\
\hline & Emotional distress - anger & Y & Anger \\
\hline & $\begin{array}{l}\text { Emotional distress - anxiety } \\
\text { PROMIS-Cancer - Anxiety }\end{array}$ & Y & Anxiety or fear \\
\hline & $\begin{array}{l}\text { Emotional distress - depression } \\
\text { PROMIS-Cancer - Depression }\end{array}$ & Y & Depression or sadness \\
\hline & General life satisfaction & Y & \multirow{4}{*}{$\begin{array}{l}\text { Positive impact of cancer on sense of self and } \\
\text { life }\end{array}$} \\
\hline & Meaning and purpose & Y & \\
\hline & Positive affect & Y & \\
\hline & Psychosocial illness impact - positive & Y & \\
\hline & Psychosocial illness impact - negative & Y & $\begin{array}{l}\text { Negative impact of cancer on sense of self and } \\
\text { life }\end{array}$ \\
\hline & Self-efficacy - general & Y & \multirow[t]{2}{*}{ Ability to perform daily activities } \\
\hline & $\begin{array}{l}\text { Self-efficacy for managing chronic conditions - } \\
\text { manage daily activities }\end{array}$ & Y & \\
\hline & $\begin{array}{l}\text { Self-efficacy for managing chronic conditions - } \\
\text { manage emotions }\end{array}$ & Y & $\begin{array}{l}\text { Ability to handle negative emotions and } \\
\text { feelings }\end{array}$ \\
\hline & $\begin{array}{l}\text { Self-efficacy for managing chronic conditions - } \\
\text { manage medications/treatment }\end{array}$ & Y & $\begin{array}{l}\text { Ability to manage recommended medications } \\
\text { and treatments }\end{array}$ \\
\hline & $\begin{array}{l}\text { Self-efficacy for managing chronic conditions - } \\
\text { manage social interactions }\end{array}$ & Y & $\begin{array}{l}\text { Ability to interact with other people to get } \\
\text { medical help or information that I need }\end{array}$ \\
\hline & $\begin{array}{l}\text { Self-efficacy for managing chronic conditions - } \\
\text { manage symptoms }\end{array}$ & Y & Ability to manage symptoms \\
\hline & $\begin{array}{l}\text { Smoking - coping expectancies all smokers; } \\
\text { daily smokers; nondaily smokers }\end{array}$ & N & \multirow[t]{9}{*}{ NA } \\
\hline & $\begin{array}{l}\text { Smoking - emotional/sensory expectancies all } \\
\text { smokers; daily smokers; nondaily smokers }\end{array}$ & N & \\
\hline & $\begin{array}{l}\text { Smoking - negative health expectancies all } \\
\text { smokers; daily smokers; nondaily smokers }\end{array}$ & $\mathrm{N}$ & \\
\hline & $\begin{array}{l}\text { Smoking - negative psychosocial expectancies } \\
\text { all smokers; daily smokers; nondaily smokers }\end{array}$ & $\mathrm{N}$ & \\
\hline & $\begin{array}{l}\text { Smoking - nicotine dependence all smokers; } \\
\text { daily smokers; nondaily smokers }\end{array}$ & $\mathrm{N}$ & \\
\hline & $\begin{array}{l}\text { Smoking - social motivations all smokers; daily } \\
\text { smokers; nondaily smokers }\end{array}$ & N & \\
\hline & $\begin{array}{l}\text { Substance use - appeal past } 30 \text { days; past } 3 \\
\text { months }\end{array}$ & $\mathrm{N}$ & \\
\hline & $\begin{array}{l}\text { Substance use - prescription pain medication } \\
\text { misuse }\end{array}$ & $\mathrm{N}$ & \\
\hline & $\begin{array}{l}\text { Substance use - severity past } 30 \text { days; past } 3 \\
\text { months }\end{array}$ & $\mathrm{N}$ & \\
\hline
\end{tabular}


eTable 2. Evaluated PROMIS Domains (cont.)

\section{Adult Domain Group}

Physical health

\section{Adult Domain}

Dyspnea - activity motivation

Dyspnea - activity requirements

Dyspnea - airborne exposure

Dyspnea - assistive devices

Dyspnea - characteristics

Dyspnea - emotional response

Dyspnea - functional limitations

Dyspnea - task avoidance

Dyspnea - time extension

Dyspnea - severity

Fatigue

PROMIS-Cancer - Fatigue

Gastrointestinal - belly pain

Gastrointestinal - bowel incontinence

Gastrointestinal - constipation

Gastrointestinal - diarrhea

Gastrointestinal - disrupted swallowing

Gastrointestinal - gas and bloating

Gastrointestinal - gastroesophageal reflux

Gastrointestinal - nausea and vomiting

Itch - activity and clothing

Itch - mood and sleep

Itch - interference

Itch - quality

Itch - scratching behavior

Itch - severity

Itch - triggers

Pain - behavior

Pain - interference

PROMIS-Cancer - Pain Interference

Pain intensity $Y$

Pain quality - neuropathic pain

Pain quality - nociceptive pain

Physical function

PROMIS-Cancer - Physical Function

- Mobility

- Upper extremity

Physical function for samples with mobility aid

users

Sexual function and satisfaction: anal

discomfort with sexual activity (for sexually active people)

Sexual function and satisfaction: bother regarding sexual function

- Female

- Male

Sexual function and satisfaction: erectile function (for sexually active men)

Sexual function and satisfaction: factors interfering with sexual satisfaction

Sexual function and satisfaction: interest in sexual activity
Included

Y

Y

Y

Y

Y

Y

Y

Y

Y

Y

Y

Y

$Y$

$\mathrm{N}$

Y

Y

Y

Y

Y

Y

Y

$\mathrm{N}$

$N$

$\mathrm{N}$

$N$

$\mathrm{N}$

N

N

Y

Y

Y

Y

Y

Y

$\mathrm{Y}$
$\mathrm{Y}$
$\mathrm{Y}$

Y

Y

Y

Y

Y

Y

$Y$

$Y$

$Y$

Y

Wording on Survey

Shortness of breath and its impact on functioning

Fatigue and its impact on functioning

Belly pain

NA

Constipation

Diarrhea

Difficulty with swallowing

Gas and bloating

Gastrointestinal reflux symptoms

Nausea and vomiting

NA

Pain and its effect on life

Ability to be physically functional$$
\text { (Ability to be physically functional }
$$

(continued on next page) 


\section{eTable 2. Evaluated PROMIS Domains (cont.)}

\begin{tabular}{|c|c|c|c|}
\hline \multirow[t]{15}{*}{ Adult Domain Group } & Adult Domain & Included & Wording on Survey \\
\hline & $\begin{array}{l}\text { Sexual function and satisfaction: oral } \\
\text { discomfort with sexual activity (for sexually } \\
\text { active people) }\end{array}$ & Y & \\
\hline & $\begin{array}{l}\text { Sexual function and satisfaction: oral dryness } \\
\text { with sexual activity (for sexually active people) }\end{array}$ & Y & \\
\hline & $\begin{array}{l}\text { Sexual function and satisfaction: orgasm - } \\
\text { ability (for sexually active people) }\end{array}$ & Y & \\
\hline & $\begin{array}{l}\text { Sexual function and satisfaction: orgasm - } \\
\text { pleasure (for sexually active people) }\end{array}$ & Y & \\
\hline & $\begin{array}{l}\text { Sexual function and satisfaction: satisfaction } \\
\text { with sex life }\end{array}$ & Y & \\
\hline & Sexual function and satisfaction: screeners & Y & \\
\hline & $\begin{array}{l}\text { Sexual function and satisfaction: sexual } \\
\text { activities } \\
\text { - Female } \\
\text { - Male }\end{array}$ & Y & \\
\hline & $\begin{array}{l}\text { Sexual function and satisfaction: therapeutic } \\
\text { aids for sexual activity } \\
\text { - Female } \\
\text { - Male }\end{array}$ & Y & \\
\hline & $\begin{array}{l}\text { Sexual function and satisfaction: vaginal } \\
\text { discomfort with sexual activity (for sexually } \\
\text { active women) }\end{array}$ & Y & \\
\hline & $\begin{array}{l}\text { Sexual function and satisfaction: vaginal } \\
\text { lubrication for sexual activity (for sexually } \\
\text { active women) }\end{array}$ & Y & \\
\hline & $\begin{array}{l}\text { Sexual function and satisfaction: vulvar } \\
\text { discomfort with sexual activity - clitoral (for } \\
\text { sexually active women) }\end{array}$ & Y & \\
\hline & $\begin{array}{l}\text { Sexual function and satisfaction: vulvar } \\
\text { discomfort with sexual activity - labial (for } \\
\text { sexually active women) }\end{array}$ & Y & \\
\hline & Sleep disturbance & Y & Sleep quality \\
\hline & Sleep-related impairment & Y & \\
\hline \multirow[t]{9}{*}{ Social health } & $\begin{array}{l}\text { Ability to participate in social roles and } \\
\text { activities }\end{array}$ & $\mathrm{Y}$ & $\begin{array}{l}\text { Ability to participate in work, and interactions } \\
\text { with family/friends }\end{array}$ \\
\hline & Companionship & Y & \\
\hline & Emotional support & Y & $\begin{array}{l}\text { Access to someone who meets emotional } \\
\text { needs }\end{array}$ \\
\hline & Informational support & Y & $\begin{array}{l}\text { Access to someone for advice or information } \\
\text { when needed. }\end{array}$ \\
\hline & Instrumental support & Y & Access to someone to help with tasks if needed \\
\hline & $\begin{array}{l}\text { Satisfaction with participation in discretionary } \\
\text { social activities ( } 11.0)\end{array}$ & Y & Isolation/Connectedness to others \\
\hline & Social isolation & Y & \\
\hline & $\begin{array}{l}\text { Satisfaction with participation in social roles } \\
\text { (v1.0) }\end{array}$ & Y & $\begin{array}{l}\text { Ability to do things for yourself, family and } \\
\text { friends }\end{array}$ \\
\hline & $\begin{array}{l}\text { Satisfaction with social roles and activities } \\
\text { (v2.0) }\end{array}$ & Y & \\
\hline
\end{tabular}

Abbreviations: NA, not applicable; PROMIS, Patient-Reported Outcomes Measurement Information System. 


\section{eTable 3. Top 5 Preferences Among Patients With PDAC and Physicians}

Domain

\begin{tabular}{|c|c|c|c|c|c|c|}
\hline Characteristic & Items & Rank & Physical & Mental & Social & General \\
\hline \multicolumn{7}{|l|}{ Patients } \\
\hline \multicolumn{7}{|c|}{ All patients $(n=135)$} \\
\hline & Pain and its effect on life & 1 & $x$ & & & \\
\hline & Ability to perform daily activities & 2 & & $x$ & & \\
\hline & Ability to manage symptoms & 3 & & & $x$ & \\
\hline & Ability to be physically functional & 4 & & $x$ & & \\
\hline & General well-being & 5 & $x$ & & & \\
\hline \multicolumn{7}{|l|}{ Sex } \\
\hline \multicolumn{7}{|c|}{ Female $(n=64)$} \\
\hline & Pain and its effect on life & 1 & $x$ & & & \\
\hline & Ability to manage symptoms & 2 & & $x$ & & \\
\hline & $\begin{array}{l}\text { Ability to participate in work and interactions with } \\
\text { family/friends }\end{array}$ & 3 & & $x$ & & \\
\hline & Ability to perform daily activities & 4 & & $x$ & & \\
\hline & Fatigue and its impact on functioning & 5 & & & $x$ & \\
\hline \multicolumn{7}{|c|}{ Male $(n=71)$} \\
\hline & Ability to be physically functional & 1 & $x$ & & & \\
\hline & $\begin{array}{l}\text { Ability to participate in work and interactions with } \\
\text { family/friends }\end{array}$ & 2 & & & $x$ & \\
\hline & Ability to perform daily activities & 3 & $x$ & & & \\
\hline & Ability to do things for yourself, family, and friends & 4 & & $x$ & & \\
\hline & General well-being & 5 & & & & $x$ \\
\hline \multicolumn{7}{|l|}{ Age } \\
\hline \multicolumn{7}{|c|}{$\leq 65$ y $(n=48)$} \\
\hline & Ability to be physically functional & 1 & $x$ & & & \\
\hline & Ability to do things for yourself, family, and friends & 2 & & $x$ & & \\
\hline & $\begin{array}{l}\text { Ability to participate in work and interactions with } \\
\text { family/friends }\end{array}$ & 3 & & & $x$ & \\
\hline & Ability to perform daily activities & 4 & & $x$ & & \\
\hline & Ability to manage symptoms & 5 & & $x$ & & \\
\hline \multicolumn{7}{|c|}{$>65$ y $(n=87)$} \\
\hline & Ability to be physically functional & 1 & $x$ & & & \\
\hline & Ability to perform daily activities & 2 & & $x$ & & \\
\hline & Pain and its effect on life & 3 & $x$ & & & \\
\hline & General well-being & 4 & & & & $x$ \\
\hline & $\begin{array}{l}\text { Ability to participate in work and interactions with } \\
\text { family/friends }\end{array}$ & 5 & & & $x$ & \\
\hline \multicolumn{7}{|c|}{ Resection status } \\
\hline \multicolumn{7}{|c|}{ Resectable $(n=44)$} \\
\hline & Ability to be physically functional & 1 & $x$ & & & \\
\hline & Ability to perform daily activities & 2 & & $x$ & & \\
\hline & Ability to do things for yourself, family, and friends & 3 & & $x$ & & \\
\hline & $\begin{array}{l}\text { Ability to participate in work and interactions with } \\
\text { family/friends }\end{array}$ & 4 & & & $x$ & \\
\hline & General well-being & 5 & & & & $x$ \\
\hline
\end{tabular}




\section{eTable 3. Top 5 Preferences Among Patients With PDAC and Physicians (cont.)}

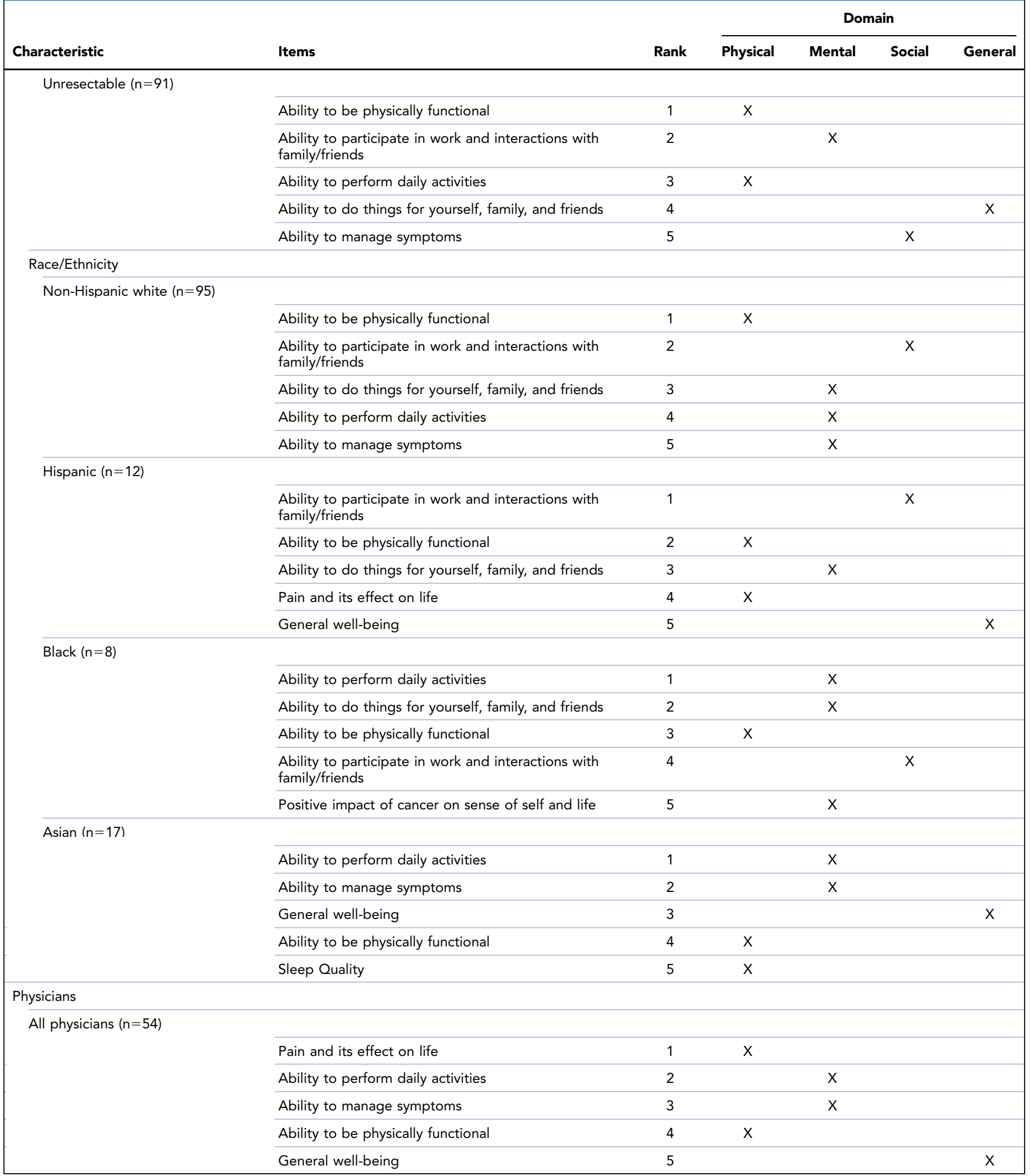




\section{eTable 3. Top 5 Preferences Among Patients With PDAC and Physicians (cont.)}

Domain

\begin{tabular}{|c|c|c|c|c|c|c|}
\hline Characteristic & Items & Rank & Physical & Mental & Social & General \\
\hline \multicolumn{7}{|l|}{ Sex } \\
\hline \multicolumn{7}{|l|}{ Female $(n=13)$} \\
\hline & Ability to be physically functional & 1 & $x$ & & & \\
\hline & Ability to do things for yourself, family, and friends & 2 & & $x$ & & \\
\hline & Ability to manage symptoms & 3 & & $x$ & & \\
\hline & Ability to perform daily activities & 4 & & $x$ & & \\
\hline & $\begin{array}{l}\text { Ability to participate in work and interactions with } \\
\text { family/friends }\end{array}$ & 5 & & & $x$ & \\
\hline \multicolumn{7}{|l|}{ Male $(n=41)$} \\
\hline & Pain and its effect on life & 1 & $x$ & & & \\
\hline & Ability to perform daily activities & 2 & & $x$ & & \\
\hline & Ability to manage symptoms & 3 & $x$ & & & \\
\hline & Ability to be physically functional & 4 & & $x$ & & \\
\hline & General well-being & 5 & & & & $\mathrm{x}$ \\
\hline \multicolumn{7}{|l|}{ Specialty } \\
\hline \multicolumn{7}{|c|}{ Medical oncology $(n=34)$} \\
\hline & Pain and its effect on life & 1 & $x$ & & & \\
\hline & Ability to perform daily activities & 2 & & $\mathrm{x}$ & & \\
\hline & Ability to be physically functional & 3 & $x$ & & & \\
\hline & Ability to manage symptoms & 4 & & $x$ & & \\
\hline & Ability to do things for yourself, family, and friends & 5 & & $x$ & & \\
\hline \multicolumn{7}{|c|}{ Other specialtya $(n=20)$} \\
\hline & Pain and its effect on life & 1 & $x$ & & & \\
\hline & Ability to manage symptoms & 2 & & $x$ & & \\
\hline & Ability to perform daily activities & 3 & & $x$ & & \\
\hline & General well-being & 4 & & & & $x$ \\
\hline & Belly Pain & 5 & $x$ & & & \\
\hline \multicolumn{7}{|c|}{ Years of experience } \\
\hline \multicolumn{7}{|l|}{$0-5(n=11)$} \\
\hline & Ability to perform daily activities & 1 & & $x$ & & \\
\hline & Pain and its effect on life & 2 & $x$ & & & \\
\hline & Ability to be physically functional & 3 & $x$ & & & \\
\hline & Ability to manage symptoms & 4 & & $x$ & & \\
\hline & Nausea and vomiting & 5 & $x$ & & & \\
\hline \multirow[t]{5}{*}{$6-10(n=18)$} & Pain and its effect on life & 1 & $x$ & & & \\
\hline & Ability to manage symptoms & 2 & & $x$ & & \\
\hline & Fatigue and its impact on functioning & 3 & $x$ & & & \\
\hline & Ability to perform daily activities & 4 & & $x$ & & \\
\hline & General well-being & 5 & & & & $x$ \\
\hline
\end{tabular}

(continued on next page) 


\section{eTable 3. Top 5 Preferences Among Patients With PDAC and Physicians (cont.)}

\begin{tabular}{|c|c|c|c|c|c|c|}
\hline Characteristic & Items & Rank & \multicolumn{4}{|c|}{ Domain } \\
\hline \multicolumn{7}{|c|}{$11-15(n=10)$} \\
\hline & Ability to perform daily activities & 2 & & $x$ & & \\
\hline & Ability to be physically functional & 3 & $x$ & & & \\
\hline & Negative impact of cancer on sense of self and life & 5 & & $\mathrm{x}$ & & \\
\hline \multicolumn{7}{|c|}{$\geq 16(n=15)$} \\
\hline & Pain and its effect on life & 1 & $\mathrm{x}$ & & & \\
\hline & Ability to perform daily activities & 2 & & $x$ & & \\
\hline & General well-being & 3 & & & & $\mathrm{x}$ \\
\hline
\end{tabular}

Abbreviation: PDAC, pancreatic ductal adenocarcinoma.

aSurgery, radiation therapy, palliative care, gastroenterology. 